\title{
White oak (Quercus fabri Hance) regenerated stump sprouts show few senescence symptoms during 40 years of growth in a natural forest
}

\author{
Honggang Sun ${ }^{*} \mathbb{D}$, Sisheng Wu and Liwen Wu
}

\begin{abstract}
Background: The relationship between physiological age of parental trees and lifespan of clonal offspring is unclear. White oak (Quercus fabri Hance) has a high sprouting capability after harvest, with the regenerated sprouts being typical clonal individuals. To determine whether regenerated sprouts undergo rapid senescence compared with the parent, the senescence levels of 5-, 10-, 20- and 40-year-old regenerated stump sprouts in a natural forest were evaluated. The antioxidative abilities and transcriptomes in these leaves and shoots were compared.

Results: Older regenerated sprouts still had robust antioxidative systems, with 40-year-old sprouts having lower peroxidation product levels but similar antioxidative enzyme activity levels compared with 5-year-old sprouts. Older leaves had greater transcriptional activities in pathways related to cell growth and division than younger leaves. However, older sprouts had some unhealthy characteristics, such as increased base excision repair levels and upregulated phagosome, proteasome and glycerophospholipid metabolism pathways in 40-year-old leaves, which indicates that DNA damage and tissue remodeling occurred more frequently than in younger leaves. Additionally, plant-pathogen interactions and MAPK signals pathways were upregulated in older shoots, which indicates that older shoots suffered from more pathogen-related biotic stress.

Conclusions: The 40-year-old sprouts still had the same vitality level as the 5-year-old sprouts, although the former had some unhealthy characteristics. We conclude that during their first 40 years of growth, regenerated stump sprouts do not begin to senesce, and that physiological age of parental trees does not significantly affect the lifespan of its clonal offspring.
\end{abstract}

Keywords: Sprout, Regeneration, Senescence, White oak, Vegetative propagation

\section{Background}

Sprouts are the main material of vegetative propagation, and many species, including European aspens (Populus tremula L.), Jabuticaba (Plinia jaboticaba Vell) and Populus euphratica, are propagated vegetatively through sprouts (Kramp et al. 2018; Oliveira et al. 2019; Tullus et al. 2020). Previously, it was reported that older parental trees had lower sprouting capabilities (Matula et al.

\footnotetext{
*Correspondence: honggangsun@caf.ac.cn

Research Institute of Subtropical Forestry, Chinese Academy of Forestry, Hangzhou 311400, China
}

\section{Springer Open}

2012). However, the link between parental tree age and regenerated sprout lifespan is unclear; do regenerated sprouts have shorter lifespans than sexually reproduced plants? Clonal trees are usually found to mature faster, and the growth of trees is limited by the maturation period (Greenwood 1995, Greenwood et al. 2010). This may occur because the clonal materials are mature; therefore, rejuvenation is implemented to delay or reverse maturation (Wendling et al. 2014). Ally et al. (2010) hypothesized that somatic mutations from parents are not eliminated by homologous recombination
๑) The Author(s). 2021 Open Access This article is licensed under a Creative Commons Attribution 4.0 International License, which permits use, sharing, adaptation, distribution and reproduction in any medium or format, as long as you give appropriate credit to the original author(s) and the source, provide a link to the Creative Commons licence, and indicate if changes were made. The images or other third party material in this article are included in the article's Creative Commons licence, unless indicated otherwise in a credit line to the material. If material is not included in the article's Creative Commons licence and your intended use is not permitted by statutory regulation or exceeds the permitted use, you will need to obtain permission directly from the copyright holder. To view a copy of this licence, visit http://creativecommons.org/licenses/by/4.0/. 
and natural selection. Consequently, ramets carry somatic mutations, which result in lower fertility rates. However, sprouts grow from calli, in which genes are reprogrammed. The telomere lengths also increase during callus culturing in species like Arabidopsis thaliana, maize, and agave (Rescalvo-Morales et al. 2016; SantosSerejo and Aguiar-Perecin 2016; Sováková et al. 2018). Thus, the aging status may be reversed in calli. In Scots pine (Pinus sylvestris Linn.), although DNA methylation levels increase with meristematic age, the growth rates and reproductive capacities of grafted shoots do not differ between old and young donors (Mencuccini et al. 2014). Owing to their long lengths, lifespans of vegetatively propagated perennial trees are hard to measure; consequently, limited studies have been published.

Accelerating senescence and leaf abscission to facilitate the survival of the next generation is a strategy of monocarpic plants (mainly annual or biennial) in response to stress, and the senescence of an entire organism occurs readily in monocarpic species (Sade et al. 2018). Unlike monocarpic plants, polycarpic plants (perennial) grow indefinitely, and plants produce new ramets to compensate for lost ones. Therefore, senescence at the organismal level rarely occurs, except when the formation of new ramets cannot offset losses (Munné-Bosch 2015). However, the accelerated senescence of leaves and roots is still harmful to polycarpic species because nutrient acquisition is curtailed. A decline in reproductive capacity is another signal of organismal senescence. White campion (Silene latifolia), a short-lived herb, produces fewer inflorescences in old age (Pujol et al. 2014), and the number of viable pollen grains per catkin per ramet decreases with clonal age in male Populus tremuloides (Ally et al. 2010). In Elymus excelsus, a bunchgrass, the reproductive capacity, but not the vegetative growth, decreases with age (Li et al., 2019a, b).

For plant organs, senescence is the final developmental stage. During this stage, several life-support systems start to decline, tissues stop growing and programmed cell death occurs on a large scale (Thomas 2013). The decline of the antioxidative system is one characteristic of senescence. Decreased antioxidase activity and antioxidant levels lead to reactive oxygen species (ROS) accumulation. ROS react with DNA and metabolites, activate several senescence-regulated NAC transcription factors, induce so-called oxidative damage and ultimately kill the cells (Berni et al. 2019; Kikuchi et al. 2020). In addition, the accumulation of gene mutations and telomere shortening are ongoing during organ life. The DNA repair system continuously upregulates to maintain genetic stability, and apoptosis occurs when DNA damage is irreparable (Abate et al. 2020). Senescence-associated genes, such as those involved in plant hormone signaling (abscisic acid-responsive element-binding transcription factors 2, 3 and 4) (Gao et al. 2016), epigenetic modifications (Arabidopsis JmjC-domain containing protein 16) (Liu et al. 2019) and pathogen defense (Senescence-associated genes 13) (Dhar et al. 2020), also play roles in senescence.

White oak (Quercus fabri Hance) is widely distributed in the northern hemisphere, and it takes more than 50 years to grow from a sapling to harvest size (Schweitzer et al. 2019). When white oaks are cut down, the stumps have a high sprouting capability (Weigel and Peng $\mathrm{C}-\mathrm{Y}$ 2002). In this study, to explore whether physiological ages of parental trees influenced the lifespans of the regenerated sprouts, the senescence levels of 5-, 10-, 20and 40-year-old white oak regenerated stump sprouts in a natural forest were evaluated and the antioxidative capabilities and transcriptomes in leaves and shoots were compared. We hypothesized that if regenerated sprouts have shorter lifespans, then the leaves and shoots of 40year-old sprouts should show obvious signs of senescence.

\section{Materials and methods}

\section{Study sites and plants}

The study sites were located at Fengshushan Forestry Farm $\left(29^{\circ} 11^{\prime} \mathrm{N}, 117^{\circ} 32^{\prime}\right.$ E) in Jiangxi Province, Southern China, which experiences a subtropical monsoon climate. The mean annual (1981-2010), monthly minimum (January) and monthly maximum (July) temperatures are $17.8^{\circ} \mathrm{C}, 10.9^{\circ} \mathrm{C}$ and $41.8^{\circ} \mathrm{C}$, respectively. The average length of the growing season is 263 days, and the mean annual precipitation is $1805 \mathrm{~mm}$. All the white oaks form one population, with sprouts being regenerated from stumps and allowed to grow for 5, 10, 20 and 40 years (groups 5a, 10a, 20a and 40a, respectively). The diameters of the stumps were similar, as were the sprouts' main-stem diameters in the same age group. Fresh leaves and shoots attached to leaves on regenerated sprouts were collected in mid-July. We used pruning shears to collect leaf and shoot samples. Because the samples were collected from one population, there were only four samples in both the $5 \mathrm{a}$ and $40 \mathrm{a}$ groups $(n=4)$ and six samples in both the 10a and 20a groups $(n=6)$. All the leaves and shoots were stored on dry ice immediately after collection, transported to the laboratory and then stored at $-80^{\circ} \mathrm{C}$.

\section{Estimates of antioxidative capabilities}

A certain weight of leaf or shoot sample was crushed in a prechilled pestle and crushed with a mortar in an appropriate volume of prechilled extraction buffer. After uniform homogenization and centrifugation at $4000 \mathrm{~g}$ for $15 \mathrm{~min}$ at $4{ }^{\circ} \mathrm{C}$, the supernatant was collected and used for biochemical analyses. 
Antioxidative capabilities were estimated by quantifying peroxidation products and antioxidase activity levels. The malondialdehyde (MDA) content was determined using a Plant MDA Assay Kit (TBA method; A003-3-1, Nanjing Jiancheng, Nanjing, China). The hydrogen peroxide $\left(\mathrm{H}_{2} \mathrm{O}_{2}\right)$ level was determined using an $\mathrm{H}_{2} \mathrm{O}_{2}$ Assay Kit $\left(\mathrm{H}_{2} \mathrm{O}_{2}\right.$ reacted with titanium salt and is then quantified at $\mathrm{OD}_{415}$; $\mathrm{A} 064-1-1$, Nanjing Jiancheng), and the superoxide anion $\left(\mathrm{O}_{2}{ }^{-}\right)$level was determined using an $\mathrm{O}_{2}{ }^{-}$Assay Kit (sulfanilamide method; R30342, Shanghai Yuanye, Shanghai, China). The activity levels of superoxide dismutase (SOD), peroxidase (POD), and catalase (CAT) were determined using the Total SOD (WST-1 method; A001-1-2, Nanjing Jiancheng), POD $\left(\mathrm{H}_{2} \mathrm{O}_{2}\right.$ catalysis method; A084-3-1, Nanjing Jiancheng) and CAT $\left(\mathrm{H}_{2} \mathrm{O}_{2}\right.$ catalysis method; A007-1-1, Nanjing Jiancheng) Assay Kits, respectively, following the manufacturer's instructions. All the leaf and shoot samples were measured three times in parallel.

\section{RNA sequencing and analysis}

Total RNA was extracted using TRIzol reagent (Invitrogen, California, USA) following the manufacturer's instructions. Quality was checked using gel electrophoresis and an Agilent 2100 Bioanalyzer (Agilent Technologies, CA, USA). Pooled libraries were sequenced on an Illumina HiSeq platform with $2 \times 150$-bp paired-end reads. After removing the adaptor and low-quality reads, the remaining clean reads were de novo assembled using Trinity software (Haas et al. 2013). Differentially expressed genes (DEGs) were determined using DESeq (R package) with the criteria fold change $>2$ and $p$-value $<0.05$ (Anders and Huber 2010). All the genes were annotated in Kyoto Encyclopedia of Genes and Genomes (KEGG) databases for functional classifications. The KEGG enrichment was performed using TBtools (Chen et al. 2020).

The gene expression pattern analysis was performed using Short Time-series Expression Miner software (Ernst and Bar-Joseph 2006) on the OmicShare tools platform (www.omicshare.com/tools).

\section{Statistical analysis}

Data were evaluated using a one-way ANOVA followed by Tukey's multiple comparisons tests. Values are expressed as means \pm SEMs.

\section{Results}

\section{Oxidative stress does not increase in older regenerated} sprouts

Oxidative stress-related indices were different for leaves and shoots, and they were not linearly correlated with sprout ages (Fig. 1). In leaves, SOD and POD activities showed no significant changes among the four tested ages, while the CAT activities in the 10a and 40a groups were lower than in the 5a and 20a groups. The MDA, $\mathrm{H}_{2} \mathrm{O}_{2}$ and $\mathrm{O}_{2}{ }^{-}$levels were lowest in the 40a group. In shoots, SOD and CAT activity levels in the 10a group were lower than in the other groups, while the POD activity in the 20a group was greater than in the $5 \mathrm{a}$ and 40a groups. However, the MDA, $\mathrm{H}_{2} \mathrm{O}_{2}$ and $\mathrm{O}_{2}{ }^{-}$levels in

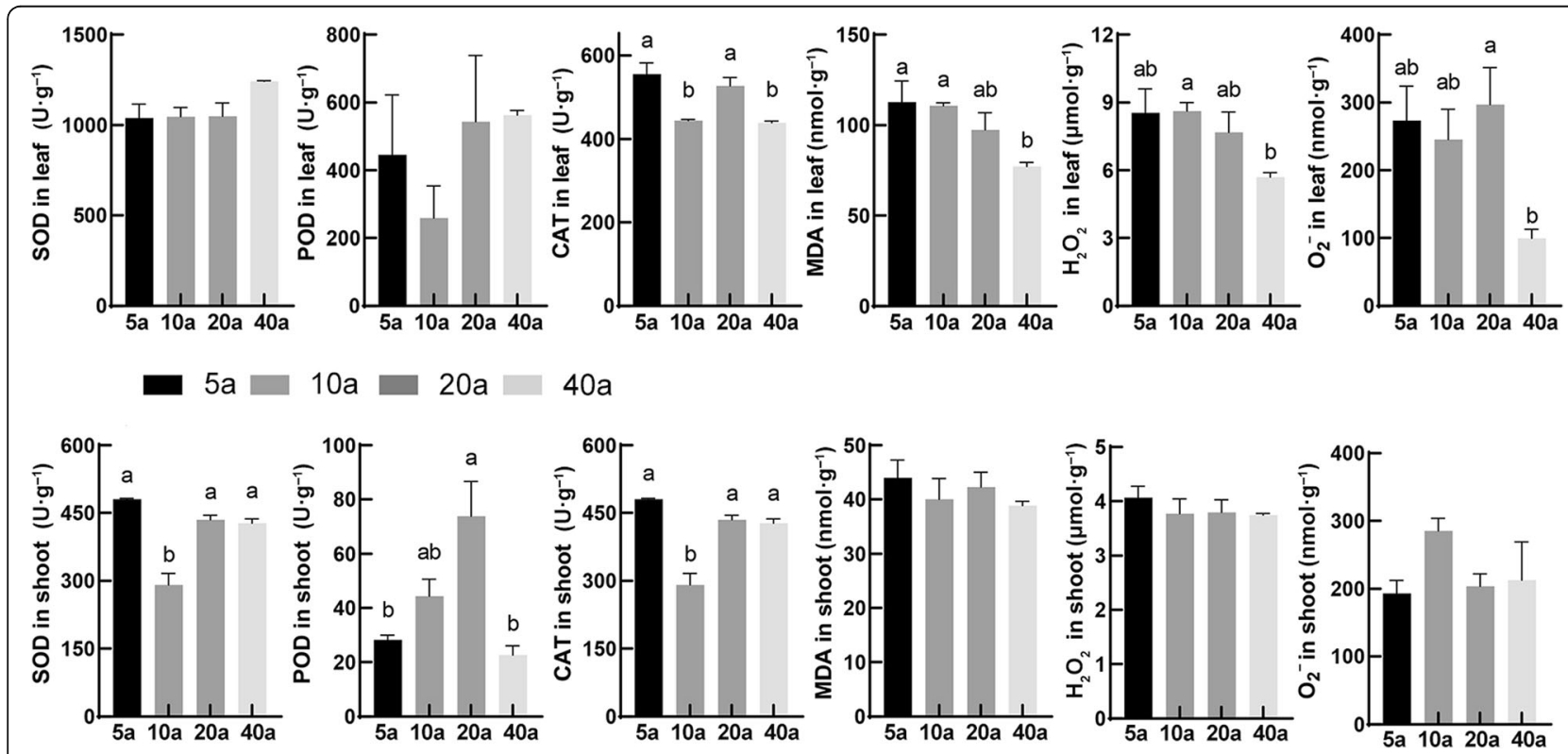

Fig. 1 Levels of antioxidative enzyme activities and peroxidation products in white oak leaves and shoots. SOD, superoxide dismutase; POD, peroxidase; CAT, catalase; MDA, malondialdehyde; $\mathrm{H}_{2} \mathrm{O}_{2}$, hydrogen peroxide, mol. $\mathrm{g}^{-1} ; \mathrm{O}_{2}^{-}$, superoxide anion. Different letters above columns indicate significant differences $(p<0.5)$ 
shoots were not significantly different among the four tested ages. Although the enzyme activities differed among the four age groups, the transcriptional levels of the SOD, POD and CAT families were not significantly changed (Fig. 2).

\section{Age-related changes at the transcriptional levels}

There were greater numbers of DEGs in leaves than in shoots (Fig. 3a). In leaves, the 10a:20a (L10:L20) comparison produced the lowest number of DEGs, with 185 and 183 DEGs up- and downregulated, respectively, in the L20 group. The 10a:40a (L10:L40) and 20a:40a (L20: L40) comparisons produced the greatest numbers of DEGs, with 5601 and 4094 DEGs upregulated in the L10 and L20 groups, respectively, and only 39 and 45 DEGs downregulated in the L10 and L20 groups, respectively. In total, 3124 DEGs were shared in the L10:L40 and L20:L40 comparisons, and 1613 DEGs were unique to the L10:L40 comparison (Fig. 3b). The 5a:10a comparison (L5:L10) produced 3831 DEGs, with 2006 and 1825 up- and downregulated, respectively, in the L10 group (Fig. 3a). In total, 1085 DEGs were shared in the L5:L10, L5:L20 and L5:L40 comparisons (Fig. 3b). It was apparent that main phyllosphere transcriptional changes occurred in the 5a-10a and 20a-40a stages.

In shoots, the transcriptional variation was minimal in the 5a:40a (S5:S40) comparison, with only five DEGs downregulated in the S40 group. The maximal variation occurred in the 5a:10a (S5:S10) comparison, with 1552 and 566 DEGs up- and downregulated, respectively, in the S10 group (Fig. 3a). The degrees of transcriptional variation were similar in the 10a:20a (S10:S20) and 20a: 40a (S20:S40) comparisons, with 735 and 631 DEGs, respectively, and most of these DEGs were upregulated in the latter groups (Fig. 3c).

\section{Enrichment analysis reveals some unhealthy characteristics}

After removing pathways with no significance $(p>0.05)$ and those that were only distinguished in a single comparison, a KEGG enrichment analysis of DEGs indicated that several pathways changed during sprout growth (Tables 1 and 2). Programmed cell death-related pathways, including apoptosis, autophagy, and DNA mismatch repair, were not markedly upregulated in older organs (Signorelli et al. 2019).

In leaves, cyanoamino acid metabolism, flavonoid biosynthesis, phenylpropanoid biosynthesis, brassinosteroid biosynthesis, starch and sucrose metabolism, cutin, suberine and wax biosynthesis, and fatty acid elongation pathways varied across ages, showing changes in four of six comparisons (Table 1 and S1). The majority of DEGs enriched in pathways related to growth (starch and sucrose metabolism, cutin, suberine and wax biosynthesis, fatty acid elongation and RNA transport), cell division (DNA replication and both porphyrin and chlorophyll

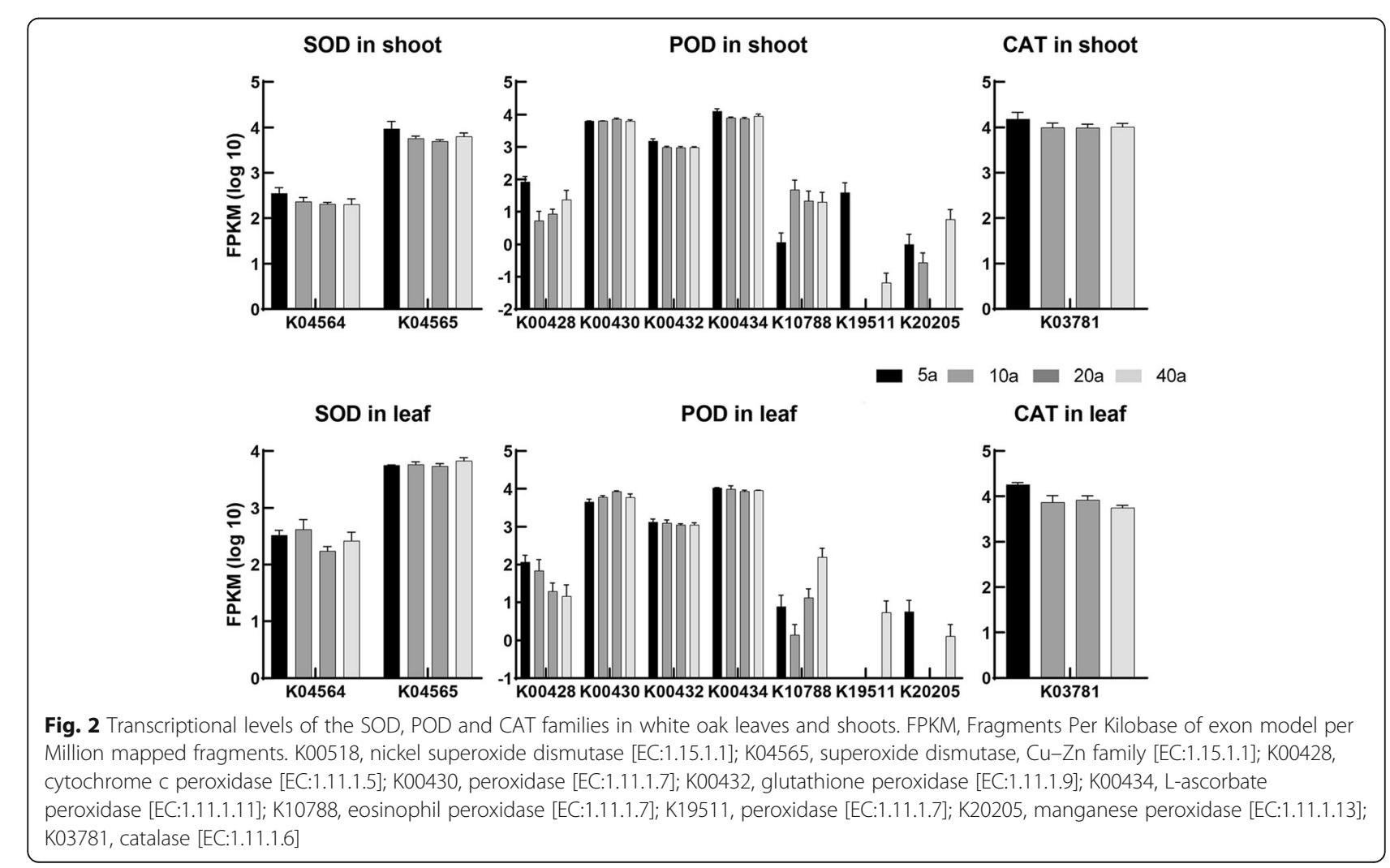




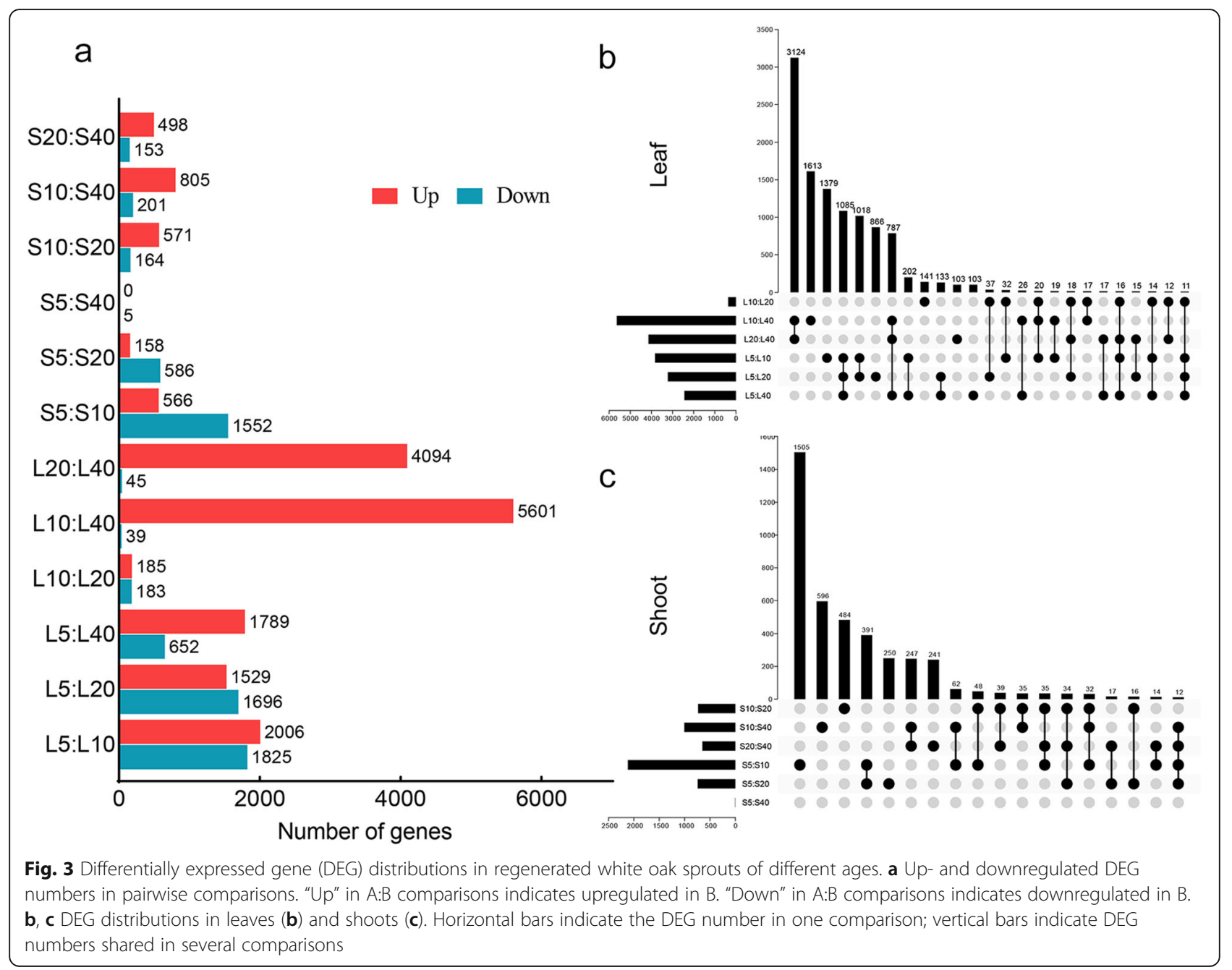

metabolism), and death (base excision repair, phagosome, proteasome and glycerophospholipid metabolism) were upregulated at greater ages (Fig. 4a).

The number of DEGs in shoots was an order of magnitude lower than in leaves, with only nine pathways varying across ages, and no altered pathways were found in the S5:S40 comparison (Table 2 and S2). Half the DEGs in the starch and sucrose metabolism pathway were downregulated in older shoots, while the other half were upregulated. This trend was unlike that in leaves (Fig. 4b). The plant-pathogen interaction pathway changed with sprout growth. The majority of the DEGs in this pathway were downregulated at the $5 a-10$ a stage but upregulated at the 10a-20a and 20a-40a stages. Accordingly, to respond to pathogens, the phagosome pathway was upregulated at 20a. The MAPK signaling pathway, a senescence-related pathway (Zhang et al. 2020), was upregulated at the 10a-20a and 20a-40a stages. The phagosome pathway was upregulated in the S20 group, and the plant hormone signal transduction pathway was upregulated in older shoots (Fig. 4b).
Genes were separated on the basis of expression profiles In leaves, six gene expression profiles were identified during regenerated sprout growth (Fig. 5). The downtrending expression profiles $(0 / 2$ and 7) contained genes related to energy, sugar, lipid, amino acid and nitrogen metabolism, which decreased with sprout age. The uptrending expression profiles (10 and 17/19) contained genes related to DNA replication, DNA repair and signal transduction, which increased with sprout age. Expression profile 18 contained genes related to MAPK signal and chlorophyll metabolism that were highly expressed in the 20a group.

In shoots, five gene expression profiles were identified during regenerated sprout growth (Fig. 6). The downtrending expression profiles ( 0 and 2$)$ contained genes related to transporter, amino acid metabolism and nitrogen metabolism, which decreased with sprout age. The up-trending expression profiles (12 and 17/19) contained genes related to signal transduction, plant-pathogen interactions and translation, which increased with sprout age. Expression profiles 11/18 contained genes related to 
Table 1 KEGG enrichment of DEGs in leaves during regenerated white oak spssssrout growth $(p<0.05)$

\begin{tabular}{|c|c|c|c|c|c|c|c|c|c|c|c|c|}
\hline \multirow[t]{2}{*}{ Pathways } & \multicolumn{2}{|c|}{ L5:L10 } & \multicolumn{2}{|c|}{ L10:L20 } & \multicolumn{2}{|c|}{ L20:L40 } & \multicolumn{2}{|c|}{ L10:L40 } & \multicolumn{2}{|c|}{ L5:L40 } & \multicolumn{2}{|c|}{ L5:L20 } \\
\hline & $U p^{a}$ & Down $^{\mathbf{b}}$ & Up & $\overline{\text { Down }}$ & Up & $\overline{\text { Down }}$ & Up & $\overline{\text { Down }}$ & Up & $\overline{\text { Down }}$ & Up & $\overline{\text { Down }}$ \\
\hline Cyanoamino acid metabolism & 21 & 12 & 0 & 8 & - & - & - & - & 17 & 7 & 13 & 10 \\
\hline Flavonoid biosynthesis & 5 & 4 & 0 & 2 & - & - & - & - & 4 & 2 & 1 & 5 \\
\hline Phenylpropanoid biosynthesis & 42 & 26 & 0 & 10 & - & - & - & - & 33 & 12 & 35 & 26 \\
\hline Brassinosteroid biosynthesis & 11 & 0 & 0 & 8 & - & - & - & - & 7 & 0 & 3 & 3 \\
\hline Starch and sucrose metabolism & 33 & 12 & 0 & 8 & - & - & - & - & 33 & 5 & 26 & 12 \\
\hline Cutin, suberine and wax biosynthesis & 8 & 2 & - & - & 10 & 0 & 11 & 0 & 5 & 1 & - & - \\
\hline Fatty acid elongation & 11 & 1 & - & - & 11 & 0 & 14 & 0 & - & - & 7 & 1 \\
\hline Phenylalanine, tyrosine and tryptophan biosynthesis & 11 & 2 & - & - & - & - & - & - & 11 & 2 & 10 & 2 \\
\hline Pentose and glucuronate interconversions & 17 & 2 & - & - & - & - & - & - & 13 & 2 & 15 & 2 \\
\hline DNA replication & 16 & 0 & - & - & - & - & 18 & 1 & 9 & 1 & - & - \\
\hline Monoterpenoid biosynthesis & 0 & 12 & - & - & - & - & - & - & 0 & 8 & 0 & 8 \\
\hline Terpenoid backbone biosynthesis & - & - & 0 & 3 & - & - & 19 & 0 & 6 & 3 & - & - \\
\hline Porphyrin and chlorophyll metabolism & - & - & - & - & 19 & 0 & 21 & 0 & - & - & - & - \\
\hline Base excision repair & - & - & - & - & 11 & 0 & 12 & 0 & - & - & - & - \\
\hline RNA transport & - & - & - & - & 63 & 0 & 90 & 0 & - & - & - & - \\
\hline Arachidonic acid metabolism & - & - & - & - & 12 & 0 & 13 & 0 & - & - & - & - \\
\hline Plant-pathogen interaction & - & - & 8 & 4 & - & - & - & - & - & - & 5 & 33 \\
\hline Phagosome & - & - & - & - & - & - & - & - & 30 & 1 & 32 & 6 \\
\hline Ribosome biogenesis in eukaryotes & - & - & - & - & 29 & 0 & 43 & 0 & - & - & - & - \\
\hline Glucosinolate biosynthesis & 0 & 3 & - & - & - & - & - & - & - & - & 0 & 2 \\
\hline Sesquiterpenoid and triterpenoid biosynthesis & 7 & 1 & - & - & - & - & - & - & 5 & 0 & - & - \\
\hline Circadian rhythm - plant & - & - & - & - & 9 & 0 & 12 & 0 & - & - & - & - \\
\hline Plant hormone signal transduction & 20 & 8 & - & - & - & - & - & - & - & - & 11 & 12 \\
\hline Glycosphingolipid biosynthesis - ganglio series & - & - & - & - & 8 & 0 & 8 & 0 & - & - & - & - \\
\hline Linoleic acid metabolism & 1 & 5 & - & - & - & - & - & - & - & - & 1 & 4 \\
\hline Proteasome & - & - & - & - & - & - & 36 & 0 & - & - & - & - \\
\hline Glycerophospholipid metabolism & - & - & - & - & 26 & 0 & - & - & - & - & - & - \\
\hline
\end{tabular}

${ }^{a}$ Down in $A: B$ comparisons indicates downregulated in $B$

${ }^{b} U p$ in $A: B$ comparisons indicates upregulated in $B$

Table 2 KEGG enrichment of DEGs in shoots during regenerated white oak sprout growth $(p<0.05)$

\begin{tabular}{|c|c|c|c|c|c|c|c|c|c|c|}
\hline \multirow[t]{2}{*}{ Pathway } & \multicolumn{2}{|c|}{ S5:S10 } & \multicolumn{2}{|c|}{ S10:S20 } & \multicolumn{2}{|c|}{ S20:S40 } & \multicolumn{2}{|c|}{ S10:S40 } & \multicolumn{2}{|c|}{ S5:S20 } \\
\hline & $U p^{a}$ & Down $^{b}$ & $\overline{U p}$ & Down & Up & Down & $\overline{U p}$ & Down & Up & Down \\
\hline Plant-pathogen interaction & 8 & 23 & 21 & 4 & 14 & 8 & 20 & 17 & 4 & 9 \\
\hline Plant hormone signal transduction & 12 & 12 & - & - & 9 & 1 & - & - & 1 & 5 \\
\hline Phenylpropanoid biosynthesis & 9 & 11 & - & - & 10 & 1 & - & - & 1 & 4 \\
\hline MAPK signaling pathway - plant & - & - & 7 & 2 & 8 & 1 & 9 & 0 & - & - \\
\hline Phagosome & - & - & 17 & 2 & - & - & 17 & 0 & - & - \\
\hline Starch and sucrose metabolism & 7 & 10 & - & - & 10 & 0 & - & - & - & - \\
\hline Ribosome & - & - & 55 & 0 & - & - & 57 & 0 & - & - \\
\hline Glutathione metabolism & 1 & 23 & - & - & - & - & - & - & 0 & 6 \\
\hline Cyanoamino acid metabolism & 5 & 1 & - & - & 9 & 0 & - & - & - & - \\
\hline
\end{tabular}




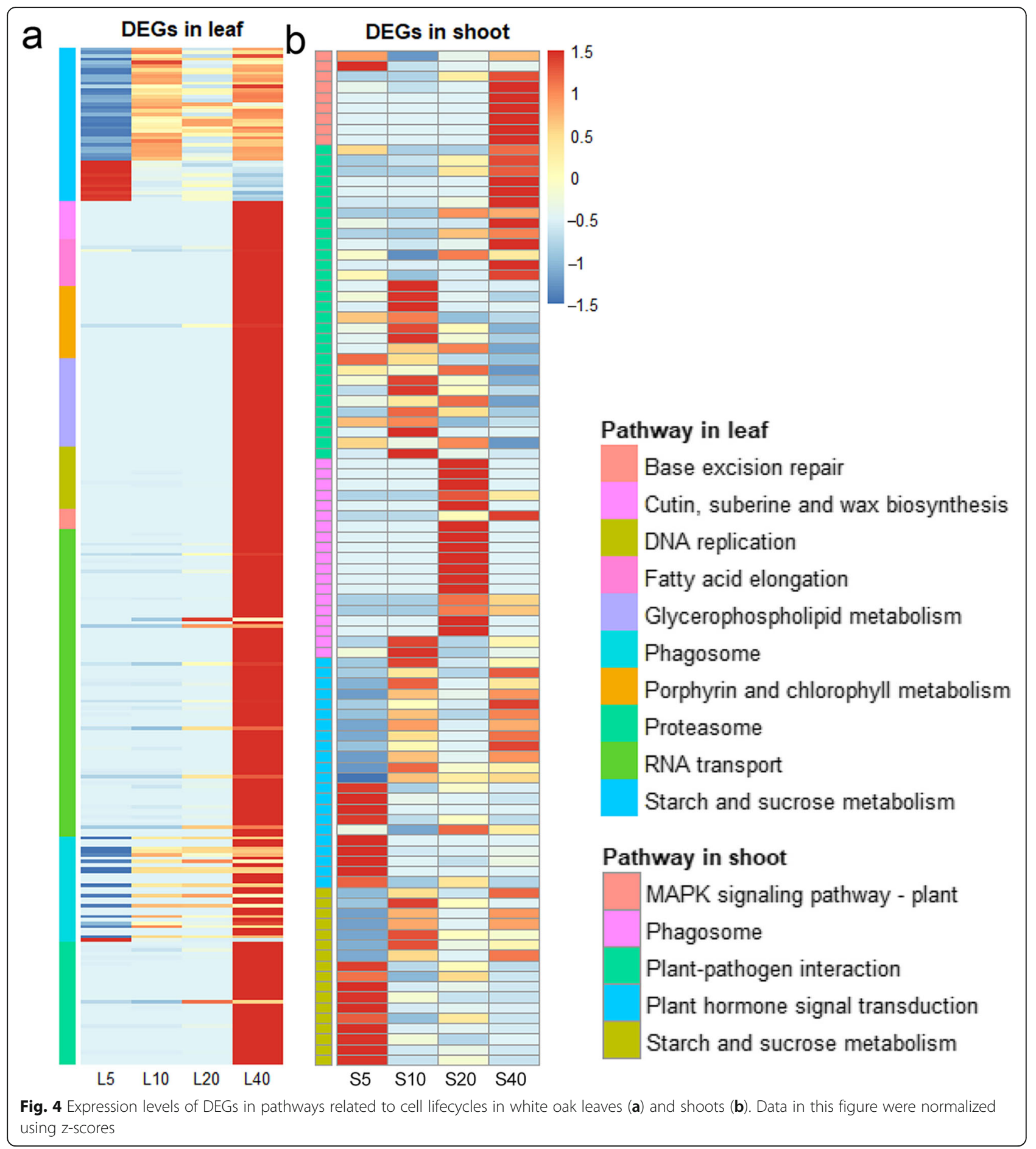

the ubiquitin system, cytochrome $\mathrm{P} 450$ and proteasome that were highly expressed in the 20 a group.

\section{Discussion}

Perennial plants grow continuously throughout their lives, with the meristem producing and rejuvenating new organs to compensate for those that are lost. The organism prevents senescence through continuous growth, which make it difficult to observe whole perennial plant senescence (Munné-Bosch 2015). The early aging of new meristematic products, that is, leaves and shoots, can indirectly prove plant senescence (Ryser et al. 2020). To ascertain whether regenerated sprouts succeed the parent's age, which indicates that regenerated sprouts have shorter lifespans and age faster than sexually reproduced sprouts, the senescence levels of leaves and shoots over 


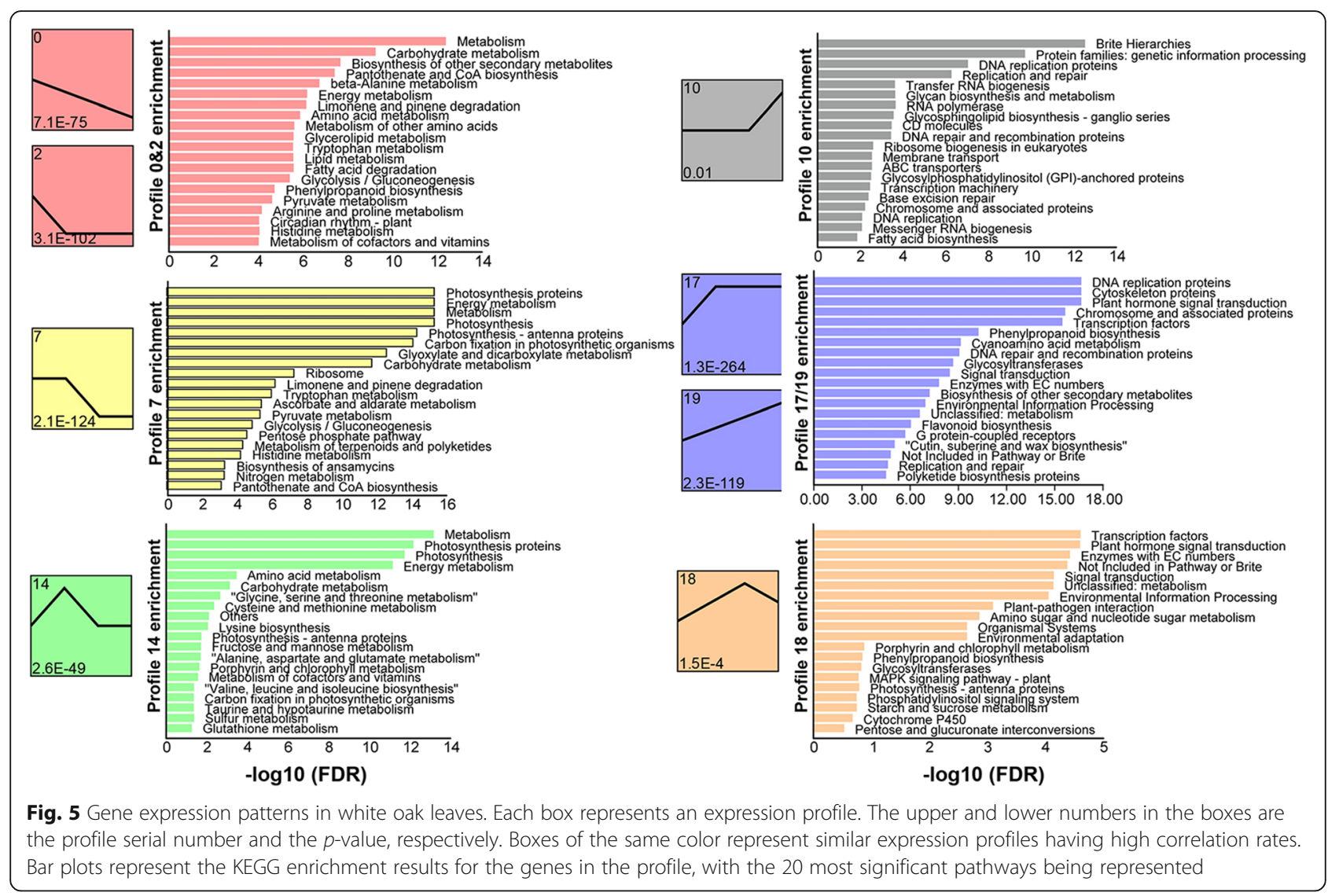

40 years of growth were estimated. We did not find enough physiological or transcriptional evidence to support that regenerated sprouts senesce in 40 years.

Senescence is a programmed cell death phenomenon that involves oxidative stress, which is indicated by a decrease in antioxidative enzyme activity levels and peroxidation product accumulation. The peroxidation products lead to further DNA damage and cell membrane disruption (Juvany et al. 2013; Sade et al. 2018). In plants, respiration and photosynthetic activities are vigorous in summer. High levels of oxygen free radicals are produced in electron transport chains, and the antioxidative defense system is important in preventing oxidative damage (Juvany et al. 2013). Here, several antioxidative enzymes showed lower activities in older sprouts, but peroxidation products did not accumulate (Figs. 1 and 2). This indicated that the 35-year period only slightly influenced the antioxidative capabilities both at the transcriptional and physiological levels. The 40-year-old regenerated sprouts still maintained the capacity to eliminate peroxidation products. This trend was different from senescent plant organs. During Tulipa gesneriana petal senescence, antioxidative enzyme activity and ROS levels increase (Wang et al. 2020), while, ROS levels increased but antioxidative enzyme activity levels decreased during rice leaf senescence (Zhou et al. 2020).
During cell senescence, macromolecules tend to be catabolized rather than synthesized; consequently, nutrients are transferred to healthy cells (Avila-Ospina et al. 2014; Qi et al. 2020; Shinozaki et al. 2020). For example, during the bamboo shoot postharvest stage, pathways, including autophagy, fatty acid degradation and amino acid metabolism, are upregulated and accompanied by organism senescence (Li et al. 2019a, b). In this study, the main differences between ages were related to metabolism (Figs. 4, 5 and 6), with older regenerated sprouts having greater synthetic reactions in biosynthetic pathways, including flavonoid, brassinosteroid, wax, fatty acids and amino acids, compared with younger ones, and even the gene expression and cell division (RNA transport and DNA replication) levels increased with age (Table 1, Fig. 4a). These transcriptional changes indicate that 40-year-old sprouts still produce enough materials to maintain a large organism. However, the base excision repair pathway was upregulated in the L40 group, which indicates that there was more DNA damage in 40-yearold leaves (Li et al. 2020). Furthermore, the upregulation of phagosome, proteasome and glycerophospholipid metabolism suggested that tissue remodeling was accompanied by DNA damage in the L40 group (Fig. 4a). Although the autophagy pathway was not activated in the 40a group, the accumulation of DNA damage was an 


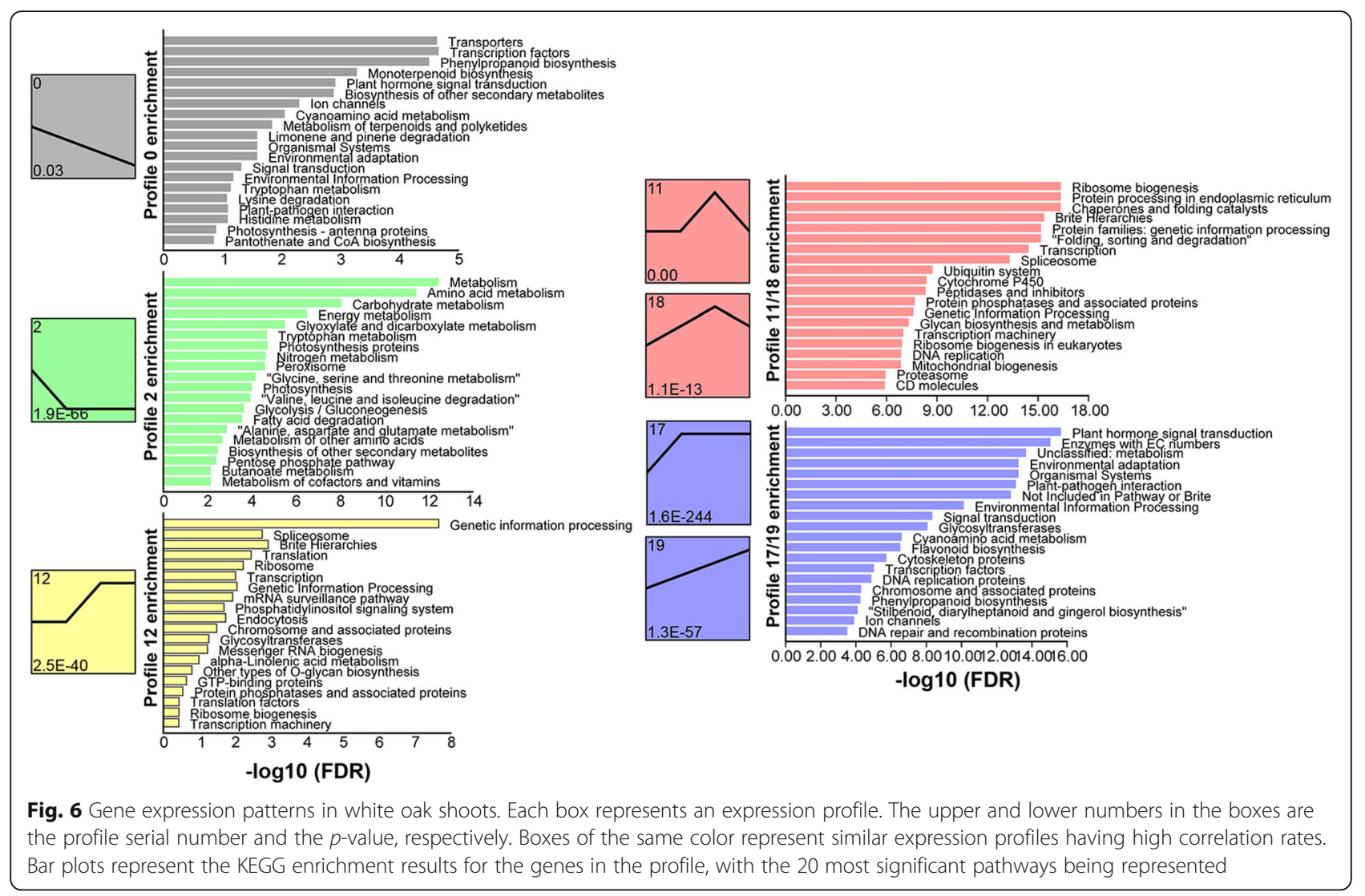

indicator of declining cell health, because it induces terminal programed cell death when the DNA damage exceeds the repair system's threshold (Yamada and Coffman 2005; Martin and Wood 2019).

Unlike leaves, shoots act as transporters rather than producers, and they have longer lifespans in deciduous plants. Thus, strong metabolic activities are not required for shoot cell production and growth; consequently, the transcriptional differences in shoots were much smaller than in leaves. The main transcriptional variation was in the plant-pathogen interaction pathway, which changed with age (Table 2), which indicates that shoots faced age-related biotic stresses. Both effector-triggered immunity and pathogen associated molecular patterns (PMAP)-triggered immunity (PTI) were influenced by sprout age (Table S2). The PTI responses produce ROS to inhibit pathogen growth (Boller and Felix 2009), and the trends in shoot SOD and CAT activity levels were similar to the trend in the plant-pathogen interaction pathway. PTI responses activate the MAPK pathway (Meng and Zhang 2013), and in this study, the MAPK pathway was simultaneously upregulated in older shoots (Fig. 4b). MAPK signals induce events, including plant senescence, ROS generation and hypersensitive response, in Arabidopsis thaliana (Zhou et al. 2009; Matsuoka et al. 2015; Kawasaki et al. 2017).
In natural forests, sprouts are not artificially rejuvenated. Therefore, if regenerated sprouts inherit the parent's age-related characteristics, then senescence symptoms should be more conspicuous. However, we did not find evidence that sprouts had inherited their parent's age-related characteristics. This has been observed in other species. A 10-year phenological study in Brazil found that Diospyros lasiocalyx trees in three forests reproduced mainly through vegetative propagation, and widespread senescence in the D. lasiocalyx populations was not observed (Aguiar et al. 2020). Pyrenean saxifrage is a monocarpic perennial species that escapes monocarpic senescence at high altitudes by clonally producing lateral rosettes that share the same root, which results in the plant becoming polycarpic (Cotado and Munné-Bosch 2020). Lomatia tasmanica is an endangered species with only one population, and vegetative propagation is the only $L$. tasmanica reproduction method. The clonal age has been determined to be 43, 600 years (Lynch et al. 1998). Thus, it appears that vegetative propagation and clonal growth prolong plant lifespans (Munne-Bosch 2014). Nevertheless, advanced clonal ages diminish or even delete the sexual propagation capacity, as seen in species such as L. tasmanica (Lynch et al. 1998), P. tremuloides (Ally et al. 2010) and Lemna minor (Barks and Laird 2015). Although these 
species still propagate vegetatively and are not senescent, the lack of sexual propagation decreases gene functional redundancy and population stress resistance.

Many forest tree species lose their regenerative capacities with age or maturation. Trees cut at more advanced ages have lower organ regenerative capabilities or regenerate organs having the parental characteristics resulting in low growth rates (Diaz-Sala 2014). However, a study reported that meristems from old-growth trees grafted onto juvenile rootstock are just as vigorous as those from mid-aged trees, although the former exhibited the old-tree parental characteristics (Greenwood et al. 2010). This indicated that meristem vigor does not decline with age and that the excepted lifespans of clonal trees are restrained by natural selection rather than genetic factors. Another study found that trees with a habitat-specific optimum body size have minimal mortality probability and maximal fertility in populations (Dani and Kodandaramaiah 2019). In this study, we hypothesized that two factors protected white oak sprouts from senescence, as follows: (1) sprouts were regenerated from stumps and their body size were smaller than parental, which indicated that the habitat was suitable for sprout growth and allowed the sprouts to absorb nutrients through the parental roots; and (2) callus cells reversed age-related effects during sprout formation, and consequently, the regenerated sprouts did not receive the parent's age-related characteristics.

Undeniably, this study has some defects, as follows. (1) Technique-related limitations. The ages of sprout parents may not be consistent and errors in predicted ages may influence the sprout phenotypes. All the parental stumps had similar diameters, and the trees are from one population. The similar genetic background ensures that any age-related errors are not large. (2) The white oak lifespan is more than 400 years; therefore, a long time period is required for senescence symptoms to become obvious (Johnson and Abrams 2009). The results in this study indicate that 40 -year-old sprouts are very healthy and are unlikely to senesce soon. (3) The experimental forest in the present study is located in a relatively comfortable environment and faces less abiotic and biotic stresses than other forests, such as windbreak forests and commercial plantations. The effects of stress resistance on regenerated sprouts have not been estimated; therefore, climate, interspecific competition and nutrient limitations may accelerate the aging of sprouts, especially clonal trees of the same genotype (Sloan and Sayer 2015; Zhang et al. 2018).

\section{Conclusions}

We found that in a natural forest, regenerated stump sprouts did not show negative signs of aging in the first 40 years of growth. Older sprouts still had robust antioxidative systems, while endocrine disorders, strong catabolism and massive autophagy were undetected, compared with younger sprouts. However, older sprouts had a few unhealthy characteristics, such as increased levels of DNA damage in leaf cells and more frequent tissue remodeling. Additionally, shoots suffered more biotic stress from pathogens, and MAPK signals were activated. The data indicated that although invisible injuries were accumulating, 40-year-old sprouts were still in the prime of their lives. The physiological age of parental trees did not significantly shorten the lifespans of the clonal offspring. Thus, although regenerated sprouts were not as strong as parental trees, they maintain the parental genotypes and help to sustain genetic diversity in harvested forests.

\section{Supplementary Information}

The online version contains supplementary material available at https://doi. org/10.1186/s40663-021-00292-1.

\section{Additional file 1 \\ Additional file 2}

\section{Abbreviations}

ROS: Reactive oxygen species; MDA: Malondialdehyde; $\mathrm{H}_{2} \mathrm{O}_{2}$ : Hydrogen peroxide; $\mathrm{O}_{2}^{-}$: Superoxide anion; SOD: Superoxide dismutase;

POD: Peroxidase; CAT: Catalase; KEGG: Kyoto Encyclopedia of Genes and Genomes; PTI: Pathogen associated molecular patterns (PMAP)-triggered immunity

\section{Acknowledgements}

We thank Lesley Benyon, PhD, from Liwen Bianji, Edanz Group China (www. liwenbianji.cn/ac), for editing the English text of a draft of this manuscript.

\section{Authors' contributions}

Honggang Sun and Liwen Wu contributed to the conception and design of the study; Sisheng Wu organized the data and performed the statistical analysis; Honggang Sun and Sisheng Wu wrote the manuscript. All authors approved the submitted version.

\section{Funding}

This research was funded by the Fundamental Research Funds for the Central Non-profit Research Institution of CAF (CAFYBB2018ZB001).

\section{Availability of data and materials}

Data sharing is not applicable to this article as no datasets were generated or analyzed during the current study.

Ethics approval and consent to participate Not applicable.

Consent for publication

Not applicable.

Competing interests

The authors declare that they have no competing interests.

Received: 23 August 2020 Accepted: 1 February 2021

Published online: 07 February 2021

\section{References}

Abate M, Festa A, Falco M, Lombardi A, Luce A, Grimaldi A, Zappavigna S, Sperlongano P, Irace C, Caraglia M, Misso G (2020) Mitochondria as 
playmakers of apoptosis, autophagy and senescence. Semin Cell Dev Biol 98: 139-153. https://doi.org/10.1016/j.semcdb.2019.05.022

Aguiar Bl, Sebbenn AM, Tarazi R, Vogado NO, Morellato LPC, Tambarussi EV, Moreno MA, Pereira LCSM, Montibeller C, Ferraz EM, Gandara FB, Kageyama PY (2020) Phenology, seed germination, and genetics explains the reproductive strategies of Diospyros lasiocalyx (Mart.) B. wall. Trop Plant Biol 13:23-35. https://doi.org/10.1007/s12042-019-09243-1

Ally D, Ritland K, Otto SP (2010) Aging in a long-lived clonal tree. PLoS Biol 8: e1000454. https://doi.org/10.1371/journal.pbio.1000454

Anders S, Huber W (2010) Differential expression analysis for sequence count data. Genome Biol 11:R106. https://doi.org/10.1186/gb-2010-11-10-r106

Avila-Ospina L, Moison M, Yoshimoto K, Masclaux-Daubresse C (2014) Autophagy, plant senescence, and nutrient recycling. J Exp Bot 65:3799-3811. https://doi. org/10.1093/jxb/eru039

Barks PM, Laird RA (2015) Senescence in duckweed: age-related declines in survival, reproduction and offspring quality. Funct Ecol 29:540-548. https:// doi.org/10.1111/1365-2435.12359

Berni R, Luyckx M, Xu X, Legay S, Sergeant K, Hausman J, Lutts S, Cai G, Guerriero G (2019) Reactive oxygen species and heavy metal stress in plants: impact on the cell wall and secondary metabolism. Environ Exp Bot 161:98-106. https://doi.org/10.1016/j.envexpbot.2018.10.017

Boller T, Felix G (2009) A renaissance of elicitors: perception of microbeassociated molecular patterns and danger signals by pattern-recognition receptors. Annu Rev Plant Biol 60:379-406. https://doi.org/10.1146/annurev.a rplant.57.032905.105346

Chen C, Chen H, Zhang Y, Thomas HR, Frank MH, He Y, Xia R (2020) TBtools - an integrative toolkit developed for interactive analyses of big biological data. Mol Plant 13:1194-1202. https://doi.org/10.1016/j.molp.2020.06.009

Cotado A, Munné-Bosch S (2020) Plasticity in the growth habit prolongs survival at no physiological cost in a monocarpic perennial at high altitudes. Ann Bot 125:413-421. https://doi.org/10.1093/aob/mcz202

Dani KGS, Kodandaramaiah U (2019) Ageing in trees: role of body size optimization in demographic senescence. Perspect Plant Ecol 36:41-51. https://doi.org/10.1016/j.ppees.2018.10.002

Dhar N, Caruana J, Erdem I, Subbarao KV, Klosterman SJ, Raina R (2020) The Arabidopsis senescence-associated gene 13 regulates dark-induced senescence and plays contrasting roles in defense against bacterial and fungal pathogens. Mol Plant Microbe Interact 33:754-766. https://doi.org/10.1 094/MPMI-11-19-0329-R

Diaz-Sala C (2014) Direct reprogramming of adult somatic cells toward adventitious root formation in forest tree species: the effect of the juvenileadult transition. Front Plant Sci 5:310. https://doi.org/10.3389/fpls.2014.00310

Ernst J, Bar-Joseph Z (2006) STEM: a tool for the analysis of short time series gene expression data. BMC Bioinformatics 7:191. https://doi.org/10.1186/1471-21 05-7-191

Gao S, Gao J, Zhu X, Song Y, Li Z, Ren G, Zhou X, Kuai B (2016) ABF2, ABF3, and ABF4 promote ABA-mediated chlorophyll degradation and leaf senescence by transcriptional activation of chlorophyll catabolic genes and senescenceassociated genes in Arabidopsis. Mol Plant 9:1272-1285. https://doi.org/10.1 016/j.molp.2016.06.006

Greenwood MS (1995) Juvenility and maturation in conifers: current concepts. Tree Physiol 15:433-438. https://doi.org/10.1093/treephys/15.7-8.433

Greenwood MS, Day ME, Schatz J (2010) Separating the effects of tree size and meristem maturation on shoot development of grafted scions of red spruce (Picea rubens Sarg.). Tree Physiol 30:459-468. https://doi.org/10.1093/treephys/tpq004

Haas BJ, Papanicolaou A, Yassour M, Grabherr M, Blood PD, Bowden J, Couger MB, Eccles D, Li B, Lieber M, MacManes MD, Ott M, Orvis J, Pochet N, Strozzi F, Weeks N, Westerman R, William T, Dewey CN, Henschel R, LeDuc RD, Friedman N, Regev A (2013) De novo transcript sequence reconstruction from RNA-seq using the trinity platform for reference generation and analysis. Nat Protoc 8:1494-1512. https://doi.org/10.1038/nprot.2013.084

Johnson SE, Abrams MD (2009) Age class, longevity and growth rate relationships: protracted growth increases in old trees in the eastern United States. Tree Physiol 29:1317-1328. https://doi.org/10.1093/treephys/tpp068

Juvany M, Müller M, Munné-Bosch S (2013) Photo-oxidative stress in emerging and senescing leaves: a mirror image? J Exp Bot 64:3087-3098. https://doi. org/10.1093/jxb/ert174

Kawasaki T, Yamada K, Yoshimura S, Yamaguchi K (2017) Chitin receptormediated activation of MAP kinases and ROS production in rice and Arabidopsis. Plant Signal Behav 12:e1361076. https://doi.org/10.1080/1 5592324.2017.1361076
Kikuchi Y, Nakamura S, Woodson JD, Ishida H, Ling Q, Hidema J, Jarvis RP, Hagihara S, Izumi M (2020) Chloroplast autophagy and ubiquitination combine to manage oxidative damage and starvation responses. Plant Physiol 183:1531. https://doi.org/10.1104/pp.20.00237

Kramp K, Schmitt T, Lang P, Jeschke M, Schäfer P, Kulanek D, Zhang X, Yu R, Thomas FM (2018) Clones or no clones: genetic structure of riparian Populus euphratica forests in Central Asia. J Arid Land 10:750-766. https://doi.org/10.1 007/s40333-018-0015-0

Li C, Li H, Yang Y (2019a) Senescence in growth and reproductive allocation in a bunchgrass. Plant Biol 21:300-306. https://doi.org/10.1111/plb.12929

Li X, Xie L, Zheng H, Cai M, Cheng Z, Bai Y, Li J, Gao J (2019b) Transcriptome profiling of postharvest shoots identifies PheNAP2- and PheNAP3-promoted shoot senescence. Tree Physiol 39:2027-2044. https://doi.org/10.1093/ treephys/tpz100

Li Z, Kim JH, Kim J, Lyu Jl, Zhang Y, Guo H, Nam HG, Woo HR (2020) ATM suppresses leaf senescence triggered by DNA double-strand break through epigenetic control of senescence-associated genes in Arabidopsis. New Phytol 227:473-484. https://doi.org/10.1111/nph.16535

Liu P, Zhang S, Zhou B, Luo X, Zhou XF, Cai B, Jin YH, Niu D, Lin J, Cao X, Jin JB (2019) The histone H3K4 demethylase JMJ16 represses leaf senescence in Arabidopsis. Plant Cell 31:430-443. https://doi.org/10.1105/tpc.18.00693

Lynch AJJ, Barnes RW, Vaillancourt RE, Cambecèdes J (1998) Genetic evidence that lomatia tasmanica (Proteaceae) is an ancient clone. Aust J Bot 46:25-33

Martin SK, Wood RD (2019) DNA polymerase zeta in DNA replication and repair. Nucleic Acids Res 47:8348-8361. https://doi.org/10.1093/nar/gkz705

Matsuoka D, Yasufuku T, Furuya T, Nanmori T (2015) An abscisic acid inducible Arabidopsis MAPKKK, MAPKKK18 regulates leaf senescence via its kinase activity. Plant Mol Biol 87:565-575. https://doi.org/10.1007/s11103-015-0295-0

Matula R, Svátek M, Kưrová J, Úradníček L, Kadavý J, Kneifl M (2012) The sprouting ability of the main tree species in central European coppices: implications for coppice restoration. Eur J Forest Res 131:1501-1511. https:// doi.org/10.1007/s10342-012-0618-5

Mencuccini M, Oñate M, Peñuelas J, Rico L, Munné-Bosch S, Salguero-Gómez R (2014) No signs of meristem senescence in old scots pine. J Ecol 102:555565. https://doi.org/10.1111/1365-2745.12219

Meng X, Zhang S (2013) MAPK cascades in plant disease resistance signaling. Annu Rev Phytopathol 51:245-266. https://doi.org/10.1146/annurev-phyto$082712-102314$

Munne-Bosch S (2014) Perennial roots to immortality. Plant Physiol 166:720-725. https://doi.org/10.1104/pp.114.236000

Munné-Bosch S (2015) Senescence: is it universal or not? Trends Plant Sci 20:713720. https://doi.org/10.1016/j.tplants.2015.07.009

Oliveira GP, Angelotti-Mendonça J, Tanaka FAO, Da Silva SR, Scarpare Filho JA (2019) Origin and development of reproductive buds in jabuticaba cv. Sabará (Plinia jaboticaba Vell). Sci Hortic 249:432-438. https://doi.org/10.1016/.jscienta.2019.02.020

Pujol B, Marrot P, Pannell JR (2014) A quantitative genetic signature of senescence in a short-lived perennial plant. Curr Biol 24:744-747. https://doi. org/10.1016/j.cub.2014.02.012

Qi H, Xia FN, Xiao S (2020) Autophagy in plants: physiological roles and posttranslational regulation. J Integr Plant Biol. https://doi.org/10.1111/jipb.12941

Rescalvo-Morales A, Monja-Mio KM, Herrera-Herrera G, Robert ML, Sánchez-Teyer LF (2016) Analysis of telomere length during the organogenesis induction of Agave fourcroydes Lem and Agave tequilana weber. Plant Cell Tiss Org 127: 135-143. https://doi.org/10.1007/s11240-016-1037-y

Ryser P, Puig S, Mueller M, Munne-Bosch S (2020) Abscisic acid responses match the different patterns of autumn senescence in roots and leaves of /ris versicolor and Sparganium emersum. Environ Exp Bot 176. https://doi.org/10.1 016/j.envexpbot.2020.104097

Sade N, del Mar Rubio-Wilhelmi M, Umnajkitikorn K, Blumwald E (2018) Stressinduced senescence and plant tolerance to abiotic stress. J Exp Bot 69:845853. https://doi.org/10.1093/jxb/erx235

Santos-Serejo JA, Aguiar-Perecin MLR (2016) Breakage-fusion-bridge cycles and de novo telomere formation on broken chromosomes in maize callus cultures. Genome 59:367-378. https://doi.org/10.1139/gen-2015-0211

Schweitzer CJ, Dey DC, Wang Y (2019) White oak (Quercus alba) response to thinning and prescribed fire in Northcentral Alabama mixed pine-hardwood forests. For Sci 65:758-766. https://doi.org/10.1093/forsci/fxz031

Shinozaki D, Merkulova EA, Naya L, Horie T, Kanno Y, Seo M, Ohsumi Y, MasclauxDaubresse C, Yoshimoto K (2020) Autophagy increases zinc bioavailability to avoid light-mediated reactive oxygen species production under zinc deficiency. Plant Physiol 182:1284-1296. https://doi.org/10.1104/pp.19.01522 
Signorelli S, Tarkowski AP, Van den Ende W, Bassham DC (2019) Linking autophagy to abiotic and biotic stress responses. Trends Plant Sci 24:413430. https://doi.org/10.1016/j.tplants.2019.02.001

Sloan S, Sayer JA (2015) Forest resources assessment of 2015 shows positive global trends but forest loss and degradation persist in poor tropical countries. Forest Ecol Manag 352:134-145. https://doi.org/10.1016/j.foreco.2 015.06.013

Sováková PP, Magdolenová A, Konečná K, Rájecká V, Fajkus J, Fojtová M (2018) Telomere elongation upon transfer to callus culture reflects the reprogramming of telomere stability control in Arabidopsis. Plant Mol Biol 98: 81-99. https://doi.org/10.1007/s11103-018-0765-2

Thomas H (2013) Senescence, ageing and death of the whole plant. New Phytol 197:696-711. https://doi.org/10.1111/nph.12047

Tullus A, Rosenvald K, Lutter R, Kaasik A, Kupper P, Sellin A (2020) Coppicing improves the growth response of short-rotation hybrid aspen to elevated atmospheric humidity. Forest Ecol Manag 459:117825. https://doi.org/10.101 6/j.foreco.2019.117825

Wang Y, Zhao H, Liu C, Cui G, Qu L, Bao M, Wang J, Chan Z, Wang Y (2020) Integrating physiological and metabolites analysis to identify ethylene involvement in petal senescence in Tulipa gesneriana. Plant Physiol Biochem 149:121-131. https://doi.org/10.1016/j.plaphy.2020.02.001

Weigel DR, Peng C-Y J (2002) Predicting stump sprouting and competitive success of five oak species in southern Indiana. Can J For Res 32:703-712. https://doi.org/10.1139/X02-042

Wendling I, Trueman SJ, Xavier A (2014) Maturation and related aspects in clonal forestry — part II: reinvigoration, rejuvenation and juvenility maintenance. New Forest 45:473-486. https://doi.org/10.1007/s11056-014-9415-y

Yamada Y, Coffman CR (2005) DNA damage-induced programmed cell death: potential roles in germ cell development. Ann N Y Acad Sci 1049:9-16. https://doi.org/10.1196/annals.1334.002

Zhang J, Gao J, Zhu Z, Song Y, Wang X, Wang X, Zhou X (2020) MKK4/MKK5MPK1/MPK2 cascade mediates SA-activated leaf senescence via phosphorylation of NPR1 in Arabidopsis. Plant Mol Biol 102:463-475. https:// doi.org/10.1007/s11103-019-00958-Z

Zhang L, Hong G, Li Z, Gao X, Wu Y, Wang X, Wang P, Yang J (2018) Assessment of the ecosystem service function of sandy lands at different times following aerial seeding of an endemic species. Sustainability 10:902. https://doi.org/1 $0.3390 /$ su10040902

Zhou C, Cai Z, Guo Y, Gan S (2009) An Arabidopsis mitogen-activated protein kinase cascade, MKK9-MPK6, plays a role in leaf senescence. Plant Physiol 150:167-177. https://doi.org/10.1104/pp.108.133439

Zhou D, Li T, Yang Y, Qu Z, Ouyang L, Jiang Z, Lin X, Zhu C, Peng L, Fu J, Peng X, Bian J, Tang W, XU J, He H (2020) OsPLS4 is involved in cuticular wax biosynthesis and affects leaf senescence in rice. Front Plant Sci 11. https:// doi.org/10.3389/fpls.2020.00782

\section{Submit your manuscript to a SpringerOpen ${ }^{\circ}$ journal and benefit from:}

- Convenient online submission

- Rigorous peer review

- Open access: articles freely available online

- High visibility within the field

- Retaining the copyright to your article

Submit your next manuscript at $\boldsymbol{\nabla}$ springeropen.com 